\title{
An Audit of Specialized Newborn Care Unit's (SNCU) Performance at a Taluk Hospital in India
}

\author{
Suman D Hegde ${ }^{1}$, Nanjundappa S Harshavardhana ${ }^{2}$, Mamatha M Hegde ${ }^{3}$ and Dinesh R Hegde ${ }^{1,4 *}$ \\ ${ }^{1}$ Mahalaxmi Memorial Hospital, Sirsi, India \\ ${ }^{2}$ Dumfries \& Galloway Royal Infirmary, Dumfries, United Kingdom \\ ${ }^{3}$ Marikamba Hospital, Sirsi, India \\ ${ }^{4}$ Pandit General Hospital, Sirsi, India
}

*Corresponding author: Dinesh R Hegde, Pandit General Hospital, Sirsi - India.

Email id: mahalaxmisrs@yahoo.com

\begin{abstract}
Objective: To report the performance of specialized newborn care unit (SNCU) at a Taluk hospital and its impact on the trends in neonatal mortality rate (NMR) over one calendar year. Existing publications on NMR are from tertiary centers that may not reflect ground realities at semirural and district hospitals.

Design: Retrospective comparative clinical study with a closed audit loop (i.e. level of evidence [LoE] III) comparing the NMR before inception of SNCU (Group I) vs. since establishing SNCU (Group II) was undertaken.

Setting: Review of all live births and neonatal deaths at SNCU of a Taluk hospital of Uttara Kannada district in Karnataka state, India.

Patients: The parturition and death registers of all deliveries over two calendar years immediately preceding the establishment of SNCU (Group I) and since its inception and regular functioning (Group II) were reviewed and details pertaining to the sex of the neonate, mode of delivery, birth weight, pre-term vs. full-term, reason for admission to SNCU, cause of death (where applicable) were collected against a standardized proforma which formed the study cohort.

Interventions: The clinical services provided to neonates by SNCU and its impact on neonatal mortality rate (NMR) was studied.

Outcomes: NMR was the key outcome studied in reporting SNCU's performance.

Results: There was a two-fold reduction in NMR in Group II and SNCU was instrumental in reducing the NMR from 6.4/1000 live births (Group I) to 3.03 (Group II). There was also a significant reduction in NMR of babies born out of caesarean sections ( $\mathrm{p}=0.04)$.

Conclusion: The SNCU was pivotal in providing round the clock clinical care that was associated with reduction in NMR and timely referrals to tertiary centers in realizing the national rural health mission's(NRHM) millennium developmental goals (MDG) towards improving maternal and child health.
\end{abstract}

Keywords: Neonate; Newborn care unit; Mortality; Taluk hospital

\section{Introduction}

The national rural health mission (NHRM) of India introduced in 2005 mandates institutionalized deliveries of all childbirths and a commitment to reduce the neonatal mortality rate (NMR), maternal mortality rate (MMR), infant mortality rate (IMR) and underfive mortality rate (U5MR) towards realizing fourth millennium developmental goals (MDG-4) [1]. It advocated Kangaroo mother 
care (KMC) practice (to facilitate better mother-baby bonding and reduce hypothermia by skin-to-skin contact) and establishment of specialized newborn care unit (SNCU) in an effort towards reducing the NMR [2]. The two key determinants that are widely used in evaluating the existing infrastructure and nation's commitment towards improving maternal and child health are NMR and MMR. They are powerful barometer of social care that is used to compare the performance of different districts/states in their commitment towards improving the well-being of mother and child $[3,4]$.

India accounts for $30 \%$ of all neonatal deaths on a global scale and majority of such deaths are largely due to preventable causes occurring in rural areas with skeletal infrastructure and healthcare facilities [5,6]. NMR accounts for $>50 \%$ of IMR and a small gain in this domain has a huge impact on overall quality of life (QoL) [7]. All published studies to date reporting NMR and morbidity statistics are from tertiary care centers and teaching hospitals that may not necessarily reflect ground realities of rural and semi-urban areas [8-10].

Increasingly SNCU and neonatal intensive care unit (NICU) are established as a public-private partnership (PPP) initiative between government health authorities and non-governmental organizations (NGO) bringing secondary/tertiary care services to area of need [11]. Preliminary results of the Chiranjeevi scheme of Gujarat government as a part of PPP initiative is encouraging [12] One such initiative was undertaken in our taluk between the Dept. of Health, Govt. of Karnataka and Rotary club / Indian medical association (IMA) leading to the establishment of SNCU (Figure 1).
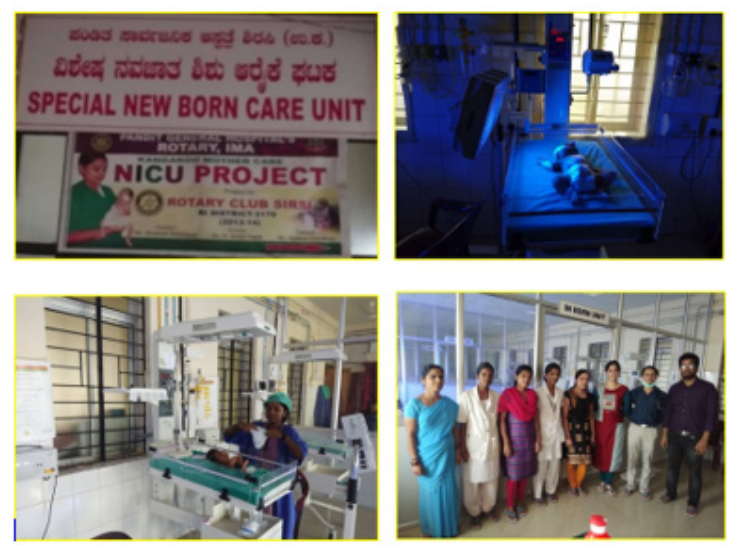

Figure 1: Specialized newborn care unit (SNCU) of Pandit general hospital $(\mathrm{PGH})$, Sirsi.

\section{Methods}

We undertook a retrospective comparative clinical study (i.e. an audit with closed loop) to establish the role and define the performance of SNCU at our taluk hospital and its impact on trends in NMR. This audit loop spanned over three years. We retrieved the parturition (i.e. birth) and mortality (i.e. death) register compiling details of all live births and neonatal deaths of a calendar year before the inception of SNCU (i.e. Group I and first part of audit loop) and since it's full functioning and clinical services (i.e. Group II and second part of the closed audit loop) respectively. The existing infrastructure and available facilities at our SNCU are listed in Table 1. We attempted to study the:

Table 1: Available facility and infrastructure at SNCU, Sirsi.

\begin{tabular}{|c|c|}
\hline Inventory & Total number \\
\hline \multicolumn{2}{|c|}{ Human Resources } \\
\hline Pediatrician (full-time) - present & 1 \\
\hline Duty doctors & 3 \\
\hline Trained nursing staff & 12 \\
\hline Counsellor & 1 \\
\hline Data operator & 1 \\
\hline \multicolumn{2}{|c|}{ Equipment and Facilities } \\
\hline Open care warmers & 10 \\
\hline Double surface phototherapy units & 2 \\
\hline Overhead phototherapy hoods & 3 \\
\hline Central oxygen supply & Yes \\
\hline
\end{tabular}




\begin{tabular}{|c|c|}
\hline Weighing machines & 3 \\
\hline Multipara monitors & 12 \\
\hline Infusion pumps & 12 \\
\hline Syringe pumps & 12 \\
\hline All drugs (including Surfactant administration) & Yes \\
\hline
\end{tabular}

i. Trends in mortality before and after the establishment of SNCU

ii. Demographic profile of SNCU admissions

iii. Identify five most common causes of admission to SNCU

iv. Other social factors and under currents - reflecting societal norms / practices

in an attempt towards improving quality of care and deliver better services. We used a standardized proforma (Figure 2) to collate the relevant information pertaining to: gender at birth, birth weight, mode of delivery, APGAR score at birth, reason for admission to / referral from SNCU (where applicable for Group II) and mortality profile for the two years (i.e. gender, death weight, age at death [in days] and cause of death). Thus, collated demographic and clinical data was recorded into excel sheet (MS Office 2017) to facilitate interpretation and analysis. Independent ' $t$ ' test with two-tailed 'p' was used to report the observations between the two groups.
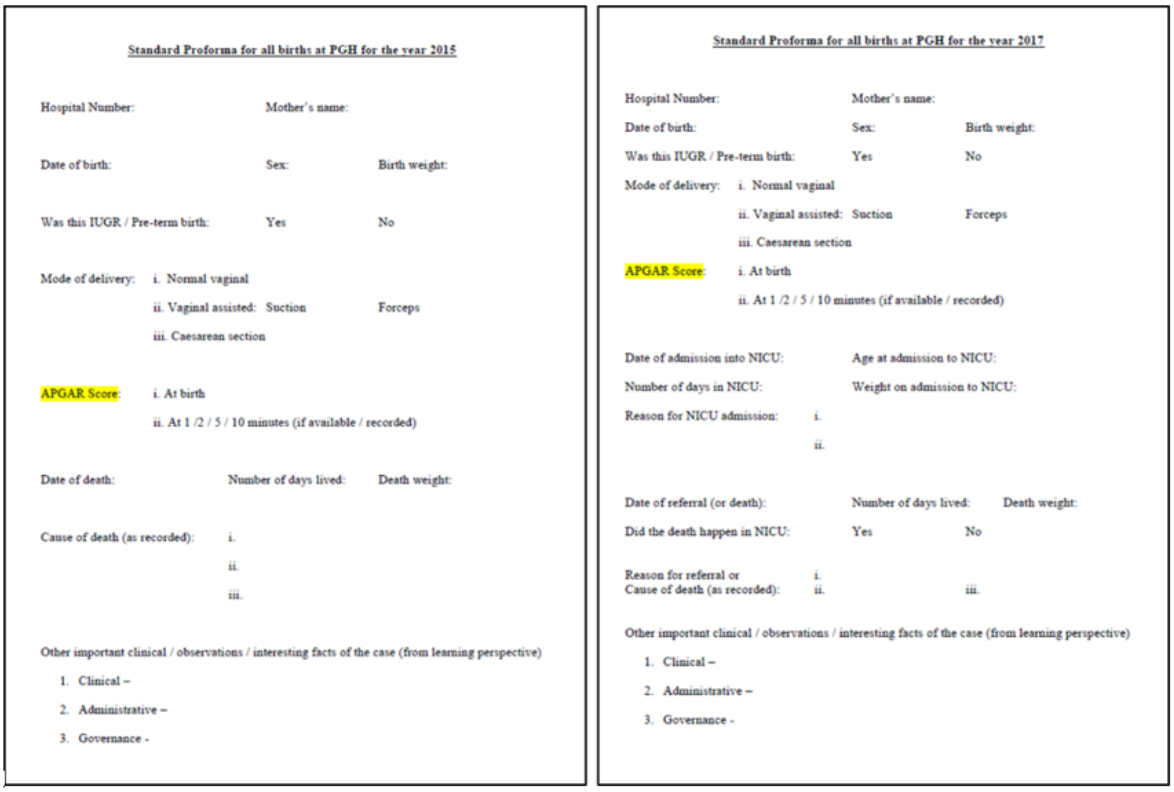

Figure 2: Standardized proforma used for data collection for the years 2015 and 2017.

We wanted to evaluate the trends in NMR and the impact of SNCU on NMR in Group II. We studied whether SNCU's infrastructure and facilities made any difference in NMR on i) caesarean vs. vaginal births and ii) pre-term/low birth weight vs. full-term/normal birth weight children. Attempts were also made to undertake a qualitative analysis to identify the most vulnerable/ at risk group of neonates where SNCU's resources could be spent towards maximizing patient outcomes.

Ethics committee (EC) and institutional review board (IRB) approval was sought from relevant administrative authorities from the office of District health officer (DHO): Directorate of health services - Government of Karnataka towards undertaking this study. No patient identifiable data or information was collected/ recorded or reported in this study. None of the authors received any funding or financial remuneration of any nature from any source (s) towards this project.

\section{Results}

The breakdown of study demographics with respect to births and deaths for gender at birth (i.e. males vs. females) and mode of delivery (i.e. vaginal births vs. caesarean section) and NMR is illustrated in Table 2. It is evident that SNCU definitely did make a difference and there was more than two-fold reductions in NMR from 6.4/1000 live births in Group I to 3.03/1000 live births for Group II. However, this was not statistically significant and $\mathrm{p}=0.10$. 
There were 742 admissions into the SNCU in Group II and the SNCU cared for roughly one-third of all live births. A small proportion of admissions were of neonates born at outside facility/ center and comparative analysis of in-house births vs. outside admissions was not feasible. The demographic breakdown of these 742 admissions is enumerated in Table 3.

Table 2: Study demographics for the two Groups - Breakdown of births and deaths by gender and mode of delivery.

\begin{tabular}{|c|c|c|c|c|c|}
\hline \multirow{3}{*}{\multicolumn{2}{|c|}{$\begin{array}{c}\text { Parameter } \\
\text { Group I (n=2658) }\end{array}$}} & \multicolumn{4}{|c|}{ Study Findings } \\
\hline & & \multicolumn{2}{|c|}{ Group I (n=2658 } & \multicolumn{2}{|c|}{ Group II $(n=2313)$} \\
\hline & & Alive & Dead & Alive & Dead \\
\hline \multirow{2}{*}{ Gender } & Male & 1361 & 12 & 1209 & 4 \\
\hline & Female & 1280 & 5 & 1097 & 3 \\
\hline \multirow{2}{*}{ Mode of Delivery } & Vaginal & 1602 & 6 & 1380 & 4 \\
\hline & Caesarean & 1039 & 11 & 926 & 3 \\
\hline \multicolumn{2}{|c|}{ Neonatal Mortality Rate } & \multicolumn{2}{|c|}{6.4} & \multicolumn{2}{|c|}{3.03} \\
\hline
\end{tabular}

Table 3: Demographics of admissions to SNCU in Group II ( $n=742)$.

\begin{tabular}{|c|c|c|}
\hline \multicolumn{2}{|c|}{ Parameter } & Total number \\
\hline \multirow{2}{*}{ Gender } & Males & 410 (4 deaths) \\
\hline & Females & 332 (1 death) \\
\hline \multirow{2}{*}{ Mode of delivery } & Vaginal & 288 (2 deaths) \\
\hline & Caesarean & 454 (3 deaths) \\
\hline \multirow{2}{*}{ Twins } & Monozygotic & $3(1 \bigcirc \& 2+)$ \\
\hline & Dizygotic & 6 \\
\hline Triplets & & 1 (all 우) \\
\hline \multirow{2}{*}{ Neonates re-admitted $(n=37)$} & Males & 21 \\
\hline & Females & 16 \\
\hline \multicolumn{2}{|c|}{ Mean stay in SNCU } & 6 days (range: $0-47$ ) \\
\hline \multicolumn{2}{|c|}{ Mean birthweight of all SNCU admissions } & 2.71 kg (range: $0.9-4.3$ ) \\
\hline \multicolumn{2}{|c|}{ Mean weight @ admission to SNCU } & $2.43 \mathrm{~kg}$ (range: $0.9-4.1$ ) \\
\hline
\end{tabular}

Table 4: Breakdown of common causes of admissions to SNCU in Group II.

\begin{tabular}{|c|c|}
\hline \multicolumn{1}{|c|}{ The big five (90\%) } & Number of Cases \\
\hline Neonatal hyperbilirubinemia & 378 \\
\hline Pre-term/IUGR/Low birthweight & 109 \\
\hline Neonatal sepsis & 64 \\
\hline Birth asphyxia/Respiratory distress syndrome & 61 \\
\hline Meconium aspiration syndrome Other causes (10\%) & 53 \\
\hline Failure to thrive (FTT)/Refusal to feed & 38 \\
\hline Dysthermia & 21 \\
\hline Hypoglycemic convulsions & 4 \\
\hline Diabetes mellitus & 4 \\
\hline Abdominal distention & 3 \\
\hline Congenital heart disease & 2 \\
\hline Cleft lip/palate & \\
\hline Severe dehydration & \\
\hline Bleeding disorder & 1 \\
\hline Laryngomalacia & 1 \\
\hline
\end{tabular}


Five key pathologies accounted for $90 \%$ of all SNCU admissions. The most common cause of admission to SNCU was neonatal hyperbilirubinemia warranting phototherapy. The breakdown of all etiologies leading to SNCU admissions are listed in Table 4. Low birth weight/pre-term births and intrauterine growth retardation (IGOR) babies accounted for $20 \%$ of all admissions $(n=149)$ and there were five deaths in this group. As they all had 'Left Against Medical Advice' (LAMA), it was not possible to identify the cause or study circumstances surrounding those deaths.

Finally, the incidence of deliveries by caesarean section was similar for the two years (approximately 40\%). However, there was a statistically significant difference in survival of neonates born in Group II as compared to Group I ( $\mathrm{p}=0.04)$. Better resuscitation facilities and trained/dedicated nursing staff coupled with SNCU's infrastructure was instrumental in these sub-set of neonates in reducing the NMR. Interestingly there was a decline in sex ratio at birth (SRB) in Group II in-comparison to Group I from 936 to 907 females per 1000 males. This trend of declining SRB observed in our taluk was also less than the Karnataka state average that is worrisome! [13,14].

In summary, the establishment of SNCU with its trained staff/ healthcare professionals with round the clock $24 \times 7$ care was associated with a two-fold reduction in NMR from 6.40/1000 to 3.03/1000 live births.

\section{Discussion}

India contributes to the highest proportion of neonatal deaths globally despite accounting for only one-fifth of all live births. The current national NMR is 28/1000 live births with a huge nationwide discrepancy between urban vs. rural areas and across different states from $<6$ (urban Kerala) to $>40$ (Uttar Pradesh, Orissa, Bihar and Rajasthan) [14]. The NRHM attempts to bridge this gap and providing universal standardized quality healthcare to all [1]. Facility-based newborn care (FBNC) recommends the implementation of simple measures like Kangaroo mother care (KMC), basic resuscitation skills and other simple communitybased interventions to reduce preventable causes of NMR esp. in low and middle income countries [2,15-16].

We undertook a retrospective clinical study (LoE III) with a closed clinical audit loop to report the performance of SNCU at a taluk hospital as most of the existing publications are from either teaching hospitals or tertiary care centers. Our SNCU was established under the guidance of senior author and provides $24 \times 7$ care round the clock for 365 days a year. We believe this to be the first study reporting the trends in NMR at an SNCU set-up as a PPP initiative in Karnataka state. Our SNCU played a decisive role in reducing the NMR that is in-line with the findings from other published studies $[11,17]$.
Despite best efforts, our study is not without its limitations. It has all the shortcomings of retrospective studies. Undertaking a research of this magnitude amidst pressing clinical commitments with long-standing staff shortage was a herculean task. Capturing the desired information from hand-written hospital registers of Group I into a proforma without any research support was a mammoth task. The APGAR score could have been better captured in the digitized era with actual number/value instead of recording them as ' 7 and above'. Nevertheless, this study was of immense introspection and identifies areas for improvement in quality of data collection. An honest attempt was made to retrieve every recorded information from registers (esp. in Group I, the predigitized era) and make meaningful sense from it to the best of our abilities. We admit our NMR of 6.4/1000 live births for 2015 and 3.03/1000 live births for 2017 to be 'too good to be true' incomparison to Karnataka state average (22-25/1000 live births) [13]. We also identified discrepancy in NMR submitted to the DHO (60 for 2015 and 45 for 2017). Despite our best efforts, we were unable to study/ascertain the cause of every neonatal death. In-addition, one month follow-up/survival status was not known of LAMA neonates. This publication highlights such practical problems and we believe establishing an 'electronic neonatal death registry' and adequate funding/staffing would improve compliance and accountability. Efforts are underway to identify such gaps, strengthen data collection and improve quality in coming years.

We believe the power of this study to be low due to small sample size (i.e. $\beta$ error). With a total of only 17 documented neonatal deaths in Group I and seven in Group II, it was not possible to undertake qualitative analysis. The deaths of children who were pre-term/IUGR/low birth weight were even fewer that precluded us from undertaking any sub-group analysis. A small proportion of deliveries (10-12\%) happened outside this taluk hospital and our team had no control over the neonatal care, outcomes or mortality of such deliveries.

Sridhar PV et al. reported the mortality and morbidity trends from a level III NICU and teaching hospital in Mandya district [18]. The NMR reported in their publication was 7.16\% (against our NMR of $0.67 \%$ ). The male:female ratio of newborns utilizing the NICU facilities was 1.45:1 and the same for our study utilizing SNCU was 1.24:1.

Modi B et al. reported the findings for the performance of four PPP SNCU in Gujarat state and found the availability of full-time pediatrician and FBNC trained nurses made a huge difference in delivering quality neonatal services that had a direct impact on NMR [11]. Our low NMR agrees with their findings as all our 12 nursing staff are FBNC trained/certified by Indira Gandhi Institute for Child health, Bengaluru and lead pediatrician has more than two decades of clinical experience and undergone advanced neonatal care training. 
Sex ratio at birth (SRB) is a key determinant reflective of prevailing societal norms and social customs. The 'Bhagyalakshmi scheme' of Govt. of Karnataka and 'Janani Shishu Suraksha Karyakram' of Govt. of India is aimed at saving/nurturing the girl child and improving the SRB towards maintaining gender balance $[19,20]$. Such state and national policies discourage sex selective abortions and legislation like pre-natal diagnostics act identifies such practices as criminal offence [21]. Interestingly despite such measures, the SRB in this study declined from 936 females/1000 males in Group I to 907 in Group II. The SRB of our study was also lower than Karnataka state average of 939 for the year 2015. We intend to identify/study factors responsible for this trend that forms grounds for further research as Karnataka has the lowest SRB amongst all the southern states in India [22].

Lastly, with advances in neonatal care, the NMR will decline in coming years. It is important to have homogenous pooled data of such birth statistics and mortality profile of different taluks/districts to facilitate meaningful sub-group analysis of high power clinical studies to produce robust evidence-based recommendations. Collaboration of professional societies (i.e. the Indian academy of pediatrics [IAP] and the Federation of obstetric and gynecological societies of India [FOGSI]) and guidance relating to training of nursing staff/research governance is desired to accomplish these goals [23].

\section{Conclusion}

Establishment of Specialized neonatal care unit (SNCU) was pivotal in reducing the neonatal mortality rate (NMR) in our Taluk hospital in a semi-rural setting. It also enabled timely referral of sick babies needing advanced intensive care / support to the tertiary center for definitive management.

\section{Acknowledgement}

To the District Health Officer (DHO) and administrative staff of DHO office.

To the dedicated nursing staff and administrative staff of Pandit General Hospital, Sirsi - Uttara Kannada; Karnataka State - India.

\section{Conflict of Interest}

All authors do not have any CoI to disclose and no funding from any source was received by any of us for this research.

\section{References}

1. National Rural Health Mission (2005) National Rural Health Mission (2005-2012)--Mission document. Indian J Public Health 49(3): 175-183.

2. Chan GJ, Valsangkar B, Kajeepeta S, Boundy EO, Wall S (2016) What is kangaroo mother care? Systematic review of the literature. J Glob Health 6(1): 010701.

3. Rajaratnam JK, Marcus JR, Flaxman AD, Wang H, Levin-Rector A, et al (2010) Neonatal, postneonatal, childhood, and under-5 mortality for 187 countries, 1970-2010: a systematic analysis of progress towards Millennium Development Goal 4. Lancet 375(9730): 1988-2008.
4. AMDD Working Group on Indicators (2002) Program note: Using UN process indicators to assess needs in emergency obstetric services: Bhutan, Cameroon and Rajasthan, India. Int J Gynaecol Obstet 77(3): 277-284.

5. Sankar M, Neogi S, Sharma J, Chauhan M, Srivastava R, et al (2016) State of newborn health in India. Journal of Perinatology 36(s3): S3-S8.

6. Rammohan A, Iqbal K, Awofeso N (2013) Reducing neonatal mortality in India: critical role of access to emergency obstetric care. PloS one 8(3): e57244.

7. Black RE, Allen LH, Bhutta ZA, Caulfield LE, De Onis M, et al (2008) Maternal and child undernutrition: global and regional exposures and health consequences. The lancet 371(9608): 243-260.

8. Jeganathan S, Rsavikmar S, Tamilmani A, Parameshwari P, Chinnarajalu $\mathrm{AV}$, et al. (2017) Neonatal mortality of sick newborns admitted in a tertiary care teaching hospital in Tamil Nadu, South India. International Journal of Contemporary Pediatrics 4(2): 399-402.

9. Ramaganeshan D, Ramu P, Teja JR, Reddy KVS (2016) Study of neonatal morbidity profile in NICU at a tertiary care teaching hospital $(\mathrm{KGH}$, Visakhapatnam). Journal of Evolution of Medical and Dental Sciences 5(67): 4809-4814.

10. Roy RN, Nandy S, Shrivastava P, Chakraborty A, Dasgupta M, et al. (2008) Mortality pattern of hospitalized children in a tertiary care hospital of Kolkata. Indian J Community Med 33(3): 187-189.

11. Modi B, Sheth A (2016) Evaluation of Public Private Partnership Model for Newborn Care Services at Trust Hospitals in High Priority Talukas of Gujarat, India. Ntl J Community Med 7(8): 716-721.

12. Bhat R, Mavalankar DV, Singh PV, Singh N (2009) Maternal healthcare financing: Gujarat's Chiranjeevi Scheme and its beneficiaries. J Health Popul Nutr 27(2): 249-258.

13. National Institution for Transforming India (NITI Aayog), Government of India http://niti.gov.in/content/sex-ratio-females-1000-males. Accessed on $18^{\text {th }}$ January 2021.

14. Sample Registration System Statistical Report (2013) Office of the Registrar General and Census Commissioner, Ministry of Home Affairs, Govt of India.

15. Bhutta ZA, Darmstadt GL, Hasan BS, Haws RA (2005) Community-based interventions for improving perinatal and neonatal health outcomes in developing countries: a review of the evidence. Pediatrics 115(2 Suppl): 519-617.

16. Maheshwari A, Kumar P, Dutta AK (2005) Facility based IMNCI. Indian J Pediatr 79(1): 75-84

17. Sharma S, Dayaratna V (2005) Creating conditions for greater private sector participation in achieving contraceptive security. Health Policy 71(3): 347-357.

18. Sridhar P, Thammanna P, Sandeep M (2015) Morbidity pattern and hospital outcome of neonates admitted in a tertiary care teaching hospital, Mandya. Int J Sci Stud 3(6): 126-129.

19. Sekhar TV (2010) Special financial incentive schemes for the girl Child in India: a review of select schemes. The Planning Commission, Government of India and United Nations Population Fund.

20. Bhushan H, Janani-Shishu Suraksha Karyakram (2012) Review. Ministry of Health and Family Welfare, Government of India, Nirman Bhawan, New Delhi.

21. Sharma S (2016) An overview on Pre-natal Diagnostic techniques Act and it's Implementation. IOSR Journal of Humanities And Social Science (IOSR-JHSS) 21(10): 62-68

22. Rajan I, Srinivasan S, Bedi S (2017) Update on Trends in Sex Ratio at Birth in India. Economic \& Political Weekly 52(11): 15.

23. Pandit S (2014) Presidential Address. J Obstet Gynaecol India 64(2): 95101. 